\title{
DE GESCHIEDENIS DER LUTHERSCHE GEMEENTE IN BERBICE
}

\section{II}

DOOR

\section{B. DE GAAY FORTMAN}

Het blijkt niet, waardoor het nog vier jaren geduurd heeft, vóór ds. Klepperbein iemand gevonden had. In de consistoriale vergadering van 19 April 1752 eerst deelde hij mee, dat de Hoogduitsche proponent Johan Heinrich Faercken, geboortig uit Eldagsen in het Hannoversche, bereid was naar Berbice te gaan. Deze kwam over, en nadat hij uitdrukkelijk verklaard had te weten, dat hij zou gaan ,op zijn eigen risico, zonder eenige praejudice en betrekkinge van dit onse Consistorium in desen", verklaarde men zich bereid hem te examineeren en straks, na goedkeuring van het beroep door directeuren der kolonie, ,als een Liefdendienst" in te zegenen. Dit alles verliep naar wensch. Faercken heette verder Faerckenius.

Zondag 15 October 1752 hield de nieuwe predikant, in Berbice aangekomen, op de plantage Solitude zijn eerste vergadering met de „bestierders”. Na een ,zeer stigtelijk” gebed en leerrede uit Filippenzen II, 12 en 13 (Alzoo, mijne geliefden, gelijk gij altijd gehoorzaam geweest zijt, niet alleen in mijne tegenwoordigheid, maar ook veelmeer nu in mijne afwezigheid, werkt dat gij zalig wordt met vreeze en beven; want God is het, die in u werkt beide het willen en het doen, naar zijn welbehagen) werden de belangen der gemeente besproken. De gouverneur had geweigerd een gebouw beschikbaar te stellen voor het houden der godsdienstoefeningen; de heer Reymers bood daarom voor dit doel zijn huis Rapenburg aan. Besloten werd daar den 22sten October 1752 voor het eerst godsdienstoefening te houden, vier ouderlingen en twee „diaconen "te kiezen. Lodewijk Abbensets zou voorloopig als voorlezer en voorzanger optreden om de kosten, aan de uitoefening van dit ambt anders verbonden, uit te sparen.

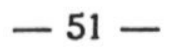


Op den genoemden dag hield ds. Faerkenius zijn ,zeer stigtelijke en zielroerende" intreepreek over Handelingen X, 42 en 43 (En hij heeft ons geboden te prediken aan het volk, en te getuigen, dat hij door God is verordend tot een rechter van levenden en dooden. Van deze geven alle profeten getuigenis, dat door zijnen naam allen, die in hem gelooven, vergeving der zonden ontvangen zullen). Abbensets, Speelman, Schirmeister en George ${ }^{1}$ ) werden ouderlingen - de eerste ook scriba - en Krzidlowsky met Johan Andreas Weber ouderlingen. De collecte had 51 gulden en 18 stuivers opgebracht. In de 's middags gehouden kerkeraadsvergadering werd besloten den gouverneur te vragen akte van gunning voor twee erven in de ontworpen stad Nieuw-Amsterdam voor kerk, predikantshuis en school, en af en toe ook in de bovendivisie kerk te houden. De kerkelijke ordonnantie van 18 September 1686 werd aanvaard met dien verstande, dat, daar ,oblaten" niet verkrijgbaar waren, ,,en dit ook een vrij middelding is", men ,ordinair spijsbrood" bij het Heilig Avondmaal zou gebruiken.

Dit alles berichtten de broeders in Berbice den 8sten Januari 1753 aan het consistorie te Amsterdam. Zij zonden daarbij de notulen hunner vergaderingen over en zegden toe dit regelmatig te zullen voortzetten. Officieel wordt nu afgezien van het verzoek als een dochterkerk aangenomen te worden, maar wel wordt weer geldelijke steun gevraagd, met name voor de kerk, die men verwacht in twee maanden gereed te zullen hebben op de voor 2000 gulden van Johannes Feer aangekochte erven, genaamd ,het canton Bern". Uit een brief van ds. Faerkenius van eenige dagen later blijkt nog, dat er 97 ledematen ingeschreven waren en dat men verwachtte sterker en grooter te zullen worden dan de gereformeerden, met wie men zich voorstelde zich ,zoo min in te laten als mogelijk is", zooals de kerkeraad schreef.

Het eenige, dat men bij het Amsterdamsche consistorie bereikte, was, dat de opdracht aan ds. Klepperbein een ruimer strekking van blijvenden aard kreeg, en met hem de ouderling Anthony Bon in commissie benoemd werd om in het algemeen de Berbicezaken te behandelen. Van geldelijken steun kon geen sprake zijn; wel volgde een berisping, dat men met kerkbouw begonnen was, vóór het door Amsterdam gewenschte fonds gevormd was.

De brieven en overgezonden notulen stellen ons in de gelegen-

1) George was als Abbensets en Schirmeister lid van het Hof van politie. In de eerste dagen van den slavenopstand leidde hij het verzet der blanken tegen de rebellen op Peereboom, waarbij hij gedood werd. Netscher, 199, 200, 400. 
heid het verloop der zaken te volgen. Johan Godfried Molwitz kreeg het opzicht over den bouw der kerk, die 60 voeten lang en 30 voeten diep zou zijn. In afwachting van de voltooiing bood de gouverneur, toen Reijmers' huis niet meer beschikbaar was, het gouvernementshuis Ruymzigt voor de kerkdiensten aan. Uit Essequebo, waar ds. Faerkenius op uitnoodiging van eenige broeders in het voorjaar van 1753 had vertoefd, werd een bijdrage van $f 200$.- overgemaakt. De bouwkosten hebben in het geheel $f$ 2500.- bedragen, waarbij ermee rekening gehouden is, dat een tweetal leden der kerk voor een deel van zijn vordering afzag.

Den 5den Augustus 1753 kon de nieuwe kerk in gebruik worden genomen. Ds. Faerkenius preekte over 1 Petrus II, 5 (en bouwt nu ook gij zelve, als levende steenen, u op tot een geestelijk huis, tot een heilig priesterdom, om te offeren geestelijke offers, die God aangenaam zijn door Jezus Christus). Ruim driehonderd menschen woonden dezen dienst bij. Dat de gouverneur genood is, wordt niet gezegd, wel leest men later van banken in de kerk voor directeur en raden. De collecte bracht dit keer $f 149.8$ op, en de mededeeling van een en ander werkte in Amsterdam zoo goed, dat het consistorie uit de ,kerkenbeurs” $f$ 600.- gaf. De preek van ds. Faerkenius werd in Nederlandsche vertaling te Amsterdam uitgegeven bij Hendrik Bruyn ,,op de cingel, op de hoek van de Gasthuysmoolensteeg" en is opgedragen aan kerkeraad en lidmaten zijner gemeente.

Men moet zich van het Nieuw-Amsterdam, waar deze kerk verrees, geen groote voorstelling maken. Hartsinck spreekt van een vlek met bijna twintig huizen, en één van die huizen was dan nog het bij de kerk behoorende predikantshuis.

Ruim een mijl voorbij de Wironjekreek, waar, gelijk gezegd, ook een gereformeerde kerk stond, verrees op den oostelijken oever van de Berbice bij de plantage Agatha een tweede Luthersche kerk, primitief van bouw, opgetrokken met kleien muren en een dak van bladeren. Dit gebouw was grooter dan dat in de stad, nl. 70 bij 40 voet, doch een preekstoel was er niet; de predikant, die om de vier maanden kwam, stond achter een 'tafel. Aldus deelen Hartsinck (286) en Netscher (183) mee.

Eenige moeilijkheden leverde de diaken Krzidlowsky op. $\mathrm{Na}$ de eerste kerkeraadsvergadering was hij er niet meer geweest. 6 Augustus 1753, toen hij weer afwezig was, gingen Schirmeister en Weber hem opzoeken; zij vonden hem bij de vendutie in het fort Amsterdam, waar hij zich verontschuldigde met de mededeeling, dat hij oud was, geen plantage, volk of vaartuig had en van plan 
was naar Holland te gaan, al te zamen redenen om ontslag te vragen. Dit laatste waren de anderen niet met hem eens. De zaak bleef sleepende, tot zij werd opgelost in de vergadering van 16 December 1753 , toen in overeenstemming met een niet nader bekend advies van ds. Klepperbein besloten werd het diakenschap af te schaffen. Diaken Weber werd daarop tot ouderling gekozen. De feitelijke toestand was ook zoo, dat er geen armen waren en er ook niet voor de diaconie gecollecteerd werd.

Niet buiten verband met deze kwestie staat het eerste geschil, dat omstreeks denzelfden tijd met de gereformeerden rees. Het schijnt, dat een middel tot stijving der kerkelijke kassen in dien tijd was het collecteeren op binnengevallen schepen en het plaatsen van bussen bij herbergiers. Voor het eerste werden telkens ouderlingen aangewezen, die op de schepen met Luthersche gezagvoerders niet onbelangrijke bedragen ophaalden. De Lutherschen hadden ook een kerkbus geplaatst bij twee herbergiers, gemeenteleden. De gereformeerden beklaagden zich daarover bij de plaatselijke overheid, die een voor hen gunstige beschikking gaf, uit kracht waarvan de deurwaarder C. F. Köhler 21 December 1753 den herbergier Christian Nicolaas Stoltenhagen en den anderen, niet genoemden, herbergier aanzegde, , ,omme de armbusse soo gij van de Luytherse gemeente in uw huys heeft immediaat te restitueeren, met interdictie omme nooyt geene andren armbussen als alleen van de gereformeerde diacony te houwden, op poene dat uw in deesen contrary doed, naer merite sult worden gecorrigeerd". Aldus luidt het exploit, dat men naar Amsterdam overzond met de vraag: Is dat in orde? Het antwoord kwam prompt: houdt U hierin ,lijdentlijk", want ge hebt geen armen te verzorgen, daar die, als zij mochten komen, ten laste van de gereformeerde diaconie zijn. Van dit laatste was men zoo zeker niet in Berbice, maar men volgde toch den ontvangen raad.

Tevergeefs werd getracht van de directie der kolonie vrijstelling te krijgen van de lasten voor kerk en slaven.

De scriba Abbensets trad in het eerste jaar na de komst van den predikant af als ouderling. Hem werd, toen kort daarop zijn vrouw overleed, uit erkenning van zijn verdiensten voor de gemeente een tweetal grafsteden ,,in het doophuisje" der kerk kosteloos afgestaan. Als voorlezer en voorzanger der gemeente werd Abbensets in 1754 opgevolgd door Coenraad Matthias Schreiber, maar een jaar later kreeg als zoodanig een aanstelling Hendrik Jansen Buse ${ }^{1}$ ).

1) Deze Buse, die in de geschiedenis der gemeente steeds meer op den 
5 December 1754 reeds overleed ds. Faerkenius. Na afloop van de begrafenis, twee dagen later, werd er kerkeraadsvergadering gehouden, waarin ouderling Speelman mededeeling deed van het korte ziekbed van den predikant. Met pijn en zwelling in de beenen was het eenige dagen tevoren begonnen, en in den nacht van 4 op 5 December had de ,huisoppasser” ouderling Molwitz, die chirurgijn was, geroepen. De dokter vond hem ,,buiten spraak en kennisse, bevangen met een catarrhus suffocativus", deed een aderlating, die eenige verlichting scheen te geven, maar geen uur later was de patiënt overleden.

De oud-ouderling Abbensets, die na zijn aftreden de kerkeraadsvergaderingen was blijven bijwonen, werd tot voorzitter benoemd in afwachting van de komst van den nieuwen predikant.

Aan het Amsterdamsche consistorie werd gevraagd weder te willen zorgen voor een „Godvrugtig, Rechtzinnig en moderaat Leeraar". Het salaris werd gebracht op $f 1200$, daar het gebruik van huisslaven, als ds. Faerkenius had gehad, kwam te vervallen. Gaarne zou men een predikant krijgen, die het Nederlandsch machtig was, maar men was bereid met een van „Hoogduitsche Taale" genoegen te nemen.

In September hadden de gecommitteerden Klepperbein en Bon al iemand gevonden: Achaz Ludolph Gottfried Deyckman, proponent in het Oude Mark-Brandenburgsche, maar deze trok zich terug. Gelukkig was aanstonds een ander bereid te gaan, ds. Johan Friedrich Matthias Gröschner, geboortig van Immekath of Minnekath in de Altmark. Hij werd met goed gevolg van wege het consistorie onderzocht en beroepen onder goedkeuring van de directie der kolonie. Ditmaal werd de beroepene niet alleen 26 November 1755 ingezegend als eene liefdedienst, waarbij hij in de Oude kerk preekte over Mattheus IX, 36-38 (En toen hij het volk zag, jammerde het hem; want zij waren versmacht en verstrooid, gelijk schapen die geen herder hebben. Toen zeide hij tot zijne jongeren: De oogst is wel groot, maar de arbeiders zijn weinigen. Bidt dan den Heer des oogstes, dat hij arbeiders in zijnen oogst zende), maar hij kreeg ook een formeelen beroepsbrief, door de leden van het consistorie te Amsterdam geteekend.

voorgrond trad en gaandeweg de plaats van Abbensets innam, kan niet dezelfde zijn als J. H. Buse opzichter-generaal, later lid van het Hof van politie, die tweemaal, 1773-1775 en 1777-1778, met anderen het bestuur der kolonie waarnam bij afwezigheid van den gouverneur, als waar is, wat Netscher meedeelt, dat die Buse omstreeks 1765 in de kolonie kwam (Netscher, 253, 258). 
2 Februari 1756 met de „Berbice vriendschap” van Texel vertrokken, kwam de nieuwe predikant 1 Mei 1756 op zijn bestemming, waar hij 16 Mei intree deed, sprekende over 2 Corinthe $\mathrm{V}$, 18-20 (En dit is alles van God, die ons met zich zelven verzoend heeft door Jezus Christus, en ons het ambt heeft gegeven, dat de verzoening predikt; want God was in Christus en verzoende de wereld met zich zelven, en rekende hun hunne zonden niet toe, en heeft onder ons het woord der verzoening opgericht. Zoo zijn wij nu boden in Christus' plaats, want God vermaant door ons; zoo bidden wij nu in Christus' plaats: Laat u met God verzoenen); des namiddags preekte hij over Hebreeën XIII, 17 (Zijt uwen leeraren gehoorzaam en onderdanig; want zij waken voor uwe zielen, als die rekenschap daarvan zullen geven; opdat zij het met vreugde doen en niet met zuchten, want dat is u niet goed).

In den loop van dit jaar deed zich een principieele kwestie voor. Oud-ouderling Abbensets zou gaan hertrouwen, en vroeg nu, of hij eerst voor den magistraat en het gerecht en daarna in de Luthersche kerk zou trouwen, dan wel alleen in de gereformeerde kerk. Men koos het eerste als ,een Loffelijk voorbeeld.... nadien denkelijk zulk een exempel door de gemeente in het vervolg zal werden gevolgd en daardoor milde giften en ondersteuning van onze kerk en Godsdienst werden verkreegen". Ds. Gröschner huwde in het jaar van zijn komst de weduwe van den ouderling Mollwitz. Met groote ijver was hij zijn werk begonnen. Er waren nu 114 lidmaten en een school was noodig. Hij schreef daarover naar Amsterdam, en meende, dat de gelden daarvoor - en voor de ook door hem weer bepleite fondsvorming - zou kunnen verkregen worden door aanleg of aankoop van een plantage, waarvoor hij geld ter leen vroeg. Het consistorie vond het plan best, maar het verstrekken van de gelden, eenige duizenden guldens, lag ,,geheel buyten [zijn] departement".

Onverwachts overleed ds. Gröschner 12 Maart 1760 na nog geen vier jaren dienst op 31-jarigen leeftijd.

Alle kerkeraadsleden en oud-leden kwamen 8 April 1760 bijeen om te beraadslagen. Abbensets kreeg weer het praesidium der vergaderingen. Tot nieuwe kerkeraadsleden waren eenige maanden tevoren gekozen Johan Hendrik Linde, die scriba werd, Christoph Jan Ernst Mellin en Jan Müller, die kort daarop overleden was, terwijl nog zitting hadden George, Beudiker, Weber, Balk en Schirmeister. Besloten werd, dat gedurende de vacature de oud-ouderlingen met de ouderlingen de kerk zouden besturen, en de godsdienstoefeningen voortgang zouden hebben met preek- 
lezen. Denzelfden dag ging een brief uit naar het consistorie in Amsterdam met verzoek opnieuw te willen zorgen voor een ,,bequaem en moderaet Predikant". In dezen brief wordt ook meegedeeld, dat de gemeente ,,vrij verswakt is door ziektens en veelvuldige sterfgevallen".

Het was midden in dat achttal jaren 1757-1765, waarin een zware epidemie de kolonie teisterde en vooral onder de Europeanen haar slachtoffers maakte. Netscher (bladz. 189) deelt mee, dat de gouverneur in zijn brieven deze ziekte koorts of roodeloop genoemd heeft, maar haar verschijnselen niet worden opgegeven (blz. 189).

Het aantal afwezigen in de kerkeraadsvergaderingen wegens ziekten van henzelf, familieleden of.... slaven was telkens zeer groot. De vergadering van 25 Augustus 1760 moet uiteengaan, omdat ,de ouderlingen E. Mellin en Abbensets worden.... aangedaan van koortsen". Op de volgende vergadering was het nog erger. 8 December 1760 kwam Abbensets in de kerk te NieuwAmsterdam, maar niemand verscheen om met hem kerkeraad te houden. Trouwens, alleen de ouderlingen Linde en Mellin vielen in de termen om aanwezig te zijn. Schirmeister en George waren ziek. Beudiker had pas vrouw en kind verloren, en niet minder dan vier ouderlingen, Weber, Johansen, Balk en Gillot (die $f 500$ aan de gemeente vermaakte) waren sedert de laatste vergadering overleden. Bij navraag aan de herbergen bleken Linde en Mellin daar niet aangekomen, waarop Abbensets besloot maar te vergaderen met den voorzanger Buse, die tot de komst van den nieuwen predikant zitting zou blijven houden. 24 Maart 1761, als weer alleen Abbensets en Buse aanwezig zijn, wordt gezegd: „,zijnde beyde tegenwoordig, Godt Lof! gezond en wel".

Uit de notulen der vergadering van 8 December 1761 blijkt de ontvangst van een brief van ds. Klepperbein, waarin erover geschreven is, dat ds. Gröschner ,gedurende zijne korte levenstijd in Berbice met veel chagrijn had moeten worstelen" en niet zoo geliefd scheen als ds. Faerkenius. Het antwoord, daarop gegeven, doet blijken, dat het huwelijk van den tweeden predikant niet gelukkig is geweest ${ }^{1}$ ), en dat hij door middel van een slaaf het

1) De weduwe Gröschner, eerder weduwe Mollwitz, hertrouwde vrij spoedig met den luitenant Jan Willem Pronk, die in 1760 met den gouverneur Van Hoogenheim in de kolonie was gekomen. In de geschiedenis van den slavenopstand wordt hij meermalen met eere genoemd (Netscher, 190, 203/4, 227). Met zijn vrouw maakte hij het den kerkeraad wel lastig om meer geld, dan haar toekwam, als weduwe Gröschner te vorderen. 
kleermakersbedrijf uitoefende, wat ,eenige ontmoeting van minachting" tengevolge had. De kerkeraad sprak daarom den wensch uit, dat de nieuwe predikant met een deugdzame vrouw zou uitkomen.

In het voorjaar van 1761 slaagden ds. Klepperbein en ouderling Bon erin een predikant voor Berbice te vinden in Salomon Fredrik Muller, geboren te Berlijn, rector op de Latijnsche school te Ahrensburg bij Hamburg, 40 jaar oud. Hij kreeg ook weer een beroepsbrief van het consistorie te Amsterdam. Daaruit blijkt, dat hij gebonden was aan ,,de rijne leere des Goddelijken Woords, gegrond in de canonike boeken der heilige Schrift, soo des ouden als nieuwen Testaments en begreepen in de drie-hoofdsymbolis, te weten het apostolische, Nicanische en athanasianische, in d'onveranderde 1530 aan Keijser Carel de vijfden te Augsburg overgegeevene Confessie, en derzelver apologie in de Smalkaldische artikelen, bij de Catechismus van Luterus en de formula concordiae". Als een liefde dienst werd hij ingezegend, gelijk zijn voorgangers. 5 October 1761, dus nadat de gemeente anderhalf jaar vacant was geweest, zette ds. Muller in Berbice voet aan wal. Hij was ongetrouwd, en beloofde, dat hij over een voorgenomen huwelijk het oordeel van den kerkeraad zou inwinnen. Dertien dagen later deed hij zijn intree, waarbij hij preekte over Lucas XXIV, 47 (en in zijnen naam boete en vergeving der zonden laten prediken, onder alle volken, te beginnen bij Jeruzalem).

Een van de eerste vragen, die de nieuwe predikant stelde, was: hoe staat het met het school houden. Het schijnt, dat de voorzanger Buse daaraan wel gedaan heeft, maar ermee had opgehouden; toen hij de burgerlijke betrekking van pakhuismeester kreeg, deed hij afstand van zijn bezoldigde kerkelijke ambten. Naar Amsterdam werd om een nieuwen voorlezer geschreven. Driehonderd gulden zou hij jaarlijks krijgen met vrij wonen en het schoolgeld. Als nieuwe ouderlingen waren inmiddels gekozen Hendrik Urban Liberti, Buse, Johan Christoph Eckardt en Christian Frederiksissen.

Hans Christian Dibbern van Friedrichshall in Noorwegen,stadsschoolmeester te Deventer, verklaarde zich bereid als schoolmeester naar Berbice te gaan. 5 October 1762 vertrok hij van Amsterdam naar Texel om met de ,Standvastigheid”, kapitein Roelof Lourens, twee maanden later aan te komen.

In Berbice was inmiddels de groote slavenopstand uitgebroken. De belangwekkende beschrijving, die Netscher daarvan geeft, gevolgd op de kaart, aan het werk toegevoegd, laat toe het geheele 
verloop van 23 Februari 1762 tot ruim een jaar later te volgen. Het vermoorden der blanken op de plantage Peereboom, het oprukken der slaven langs de rivier, de bedreiging van fort Nassau, dat door directeur en raden om de onwil bij burgers en militairen om daar stand te houden moest worden prijsgegeven, de vlucht naar de schepen met hun lafhartige kapiteins en bemanning, tot eindelijk op fort St. Andries na de geheele kolonie nagenoeg in handen der opstandelingen was - het is alles een groot drama van angst en dood, waarin de moed van den gouverneur bijna alleen stond tegenover de blooheid der anderen.

Dibbern, heeft tot groot genoegen van de gemeente zich aan het werk gezet had, maar die werkzaamheid heeft niet lang kunnen duren.

De slavenopstand belette ook uitvoering te geven aan eenige voorgenomen herstellingen aan de kerk. Ds. Muller had al eerder ook klachten over den toestand, waarin zijn pastorie, met name zijn studeerkamer, verkeerde, maar deze klachten werden in den kerkeraad weinig vriendelijk ontvangen. Men ging eens kijken en vond, dat er ,,veele menschen, ja zelfs van de Regering, zijn, die zulke goede woningen niet hebben".

Dit schijnt het begin van meer moeilijkheden te zijn geweest. 3 Januari 1763 was er kerkeraad, en vroeg ds. Muller een vrijwillige bijdrage, daar alles zoo duur was geworden, en tevens beklaagde hij zich erover, dat Abbensets bij een afrekening hem $f$ 100.- - te veel afgehouden had. In plaats van antwoord kreeg hij het verzoek het lidmatenboek en het doopboek af te geven. Daarop liep hij de vergadering uit en weigerde aan twee hem nagezonden ouderlingen de boeken af te geven, vóór hij antwoord op zijn vragen zou hebben gekregen. De vergadering herinnerde zich daarop, dat bij een voorgaande gelegenheid was gebleken, dat niet één nieuw lidmaat aangeteekend was en met name had men gemist den ouderling Eckardt en dr. Bas $\left.{ }^{1}\right)$. Er werd besloten den predikant „op 't aldervriendelijkste te versoeken dat zijn WelEerw. zig dog in 't toekoomende het waare welzijn van deze gemeente gelieft ter herten te laaten gaan, en ouderlingen niet verder doen treuren en sugten over aanstootelijke en onstigtelijke naareedenen en gespreeken in gezelschappen, maar dat Zijn WelEerw. zig alomme voorzigtig gelieft te gedraagen, opdat de gemeente zoowel met zijn WelEerw. goede wandel als met de suyvere leere des

\footnotetext{
1) Netscher, 199 deelt mee, dat dr. Jan Jacob Bass, chirurgijn-majoor, in den slavenopstand levend werd gevild en daarna doodgeslagen.
} 
Goddelijken Woords mag gestigt worden; dat zijn WelEerw. ook zijn werk gelieft te maaken, om de nieuw aankoomende geloofsgenooten over de gronden van hun Christelijke belijdenisse te ondervraagen, de attestatien, die zij vertoonen, te ondersoeken en daaromtrent te doen zooals zijn Eerw. in conscientie bevinden zal te behooren, ten ijnde dat dezelve als ledemaaten dezer gemeente in het kerkboek bij zijn WelEerw. ingeschreven en ook aan de ouderlingen bekend moogen worden, om ze mede tot contribueeren te kunnen aanmaanen, gelijk zulks door wijlen d'WelEerw. Heeren Predikanten Faerkenius en Gröschner is geschied, en het voorbeeld in het kerkboek gevonden word, alsook zijn WelEerw. d'Heer Muller naa zijn komst in de colonie van alles vriendelijk onderrigt gegeven is".

Hierna volgt de mededeeling, dat de kerkeraad de verzoeken van ds. Muller met algemeene stemmen had afgewezen.

Daarop kwam de predikant weer ter vergadering en werden de notulen gelezen, maar hij weigerde die te teekenen, zooals alle aanwezige ouderlingen, Abbensets, Schirmeister, George, Buse, Eckardt, Hendrik en Schweitzer deden, en verliet, al protesteerende, de vergadering weer ,,zonder God te danken”.

Netscher (blz. 202 e.v.) heeft het lafhartig gedrag van burgers en schepelingen, door mij reeds genoemd, vrij uitvoerig geschetst. Gouverneur Van Hoogenheim had met behulp van de naar fort Nassau te hoop geloopen vluchtelingen daar willen standhouden maar hun eenige begeerte was in de schepen te gaan en naar de monding der rivier af te zakken. Eenmaal op de schepen, washet eenig streven van passagiers en bemanning, onder welke genoemd worden de kapiteins Cock, Rameloo en Pijnappel, om naar het vaderland te vertrekken, waartoe de gouverneur echter geen toestemming wilde geven. Onder hen, die hun heil op de schepen zochten komen, eenige namen voor, reeds genoemd of in het vervolg nog te noemen als behoorende tot de Luthersche gemeente, als Hans Christiaan Dibbern, W. van Lentzing, H. J. Buse, luitenant, en J. C. Eckardt, vaandrig der burgerij, Pieter Zweitser, (Hartsinck I, 384, 386). Slechts 12 burgers verklaarden zich bereid tegen de opstandelingen tot het uiterste stand te houden. Ten slotte heeft toen de gouverneur het vertrek der bloohartigen gelast, omdat hun langer blijven slechts zonder nut de levensmiddelenvoorraad zou doen slinken. Dat de last om te vertrekken alleen gegeven werd om de gebleken onwil tot hulpverleening tegen de opstandelingen en geenszins behoorde tot des gouverneurs verdedigingsplan van de kolonie, blijkt duidelijk. Den gerefor- 
meerden predikant ds. Van Petersom Ramring heeft de gouverneur zelfs uitdrukkelijk verzocht te blijven bij het overschot zijner gemeente, dat in zijn droeven staat zijn stichting en vertroosting wel bijzonder noodig had. Ook dit verzoek was tevergeefsch.

Het is noodig deze gang van zaken hier vast te leggen, omdat meer dan één dezer vluchtelingen, en onder hen ook ds. Muller, het heeft doen voorkomen, alsof hij door te vertrekken niet anders gedaan heeft dan opvolgen het bevel van den gouverneur.

10 April 1763 was de Luthersche predikant aan boord van het schip ,Berbice welvaaren”, van kapitein Rameloo waar hij van den president-ouderling Schirmeister zijn traktement over de laatst verschenen drie maanden in ontvangst nam. Een afschrift der desbetreffende verklaring ligt in het Luthersche archief met het afschrift van een brief, door ds. Muller drie dagen later tot den gouverneur gericht. Uit dien brief blijkt, dat hij met ,,capt. Koch" ging vertrekken, en daar zijn kerkeraad hem ,zonder aangetoonte redenen" een attestatie weigerde, vroeg hij den gouverneur aan ds. Klepperbein op te zenden een verklaring, ,dat Sal. Fridr. Muller als toonder deezes $1^{1} / 2$ jaar lang in de Hollandsche Colonie de Berbice Evangelische Lutherse Predikant geweezen en van wegens de rebellie der Negers wegvluchten moeten".

Gelet op zijn houding tegenover ds. Van Petersom Ramring is het aan geen twijfel onderhevig, dat de gouverneur niet aan dit verzoek heeft voldaan. Er was voor ds. Muller te minder reden om te vluchten en zijn gemeente in den steek te laten, omdat de negers hem en zijn kerk opzettelijk gespaard hadden. Ds. Van Petersom Ramring was bij de overmeestering van Peereboom wel gevangen genomen, maar door het hoofd der opstandelingen als boodschapper naar den gouverneur gezonden. De beide kerken aan de Wironjekreek waren verbrand en ook de gereformeerde kerk was met fort Nassau in vlammen opgegaan, maar de daarbuiten in Nieuw-Amsterdam gelegen Luthersche kerk was met de pastorie ontzien, naar men wil, omdat de negers zeiden, dat de blanken daar met God spraken (Hartsinck I, 286 en 467).

21 April 1763 berichtten Abbensets, Schirmeister en Buse als ,de overgeblevene ouderlingen, thans uyt makende den kerkeraad" het gebeurde aan het Amsterdamsche consistorie. Met Dibbern, den schoolmeester, die met dezelfde gelegenheid als ds. Muller vertrokken was, had men medelijden, maar deze laatste had zijn gemeente verlaten en was zonder afscheid vertrokken, hoewel ondanks haar zeer droevige omstandigheden de gemeente 
niet had opgehouden te bestaan. Uit de bijgevoegde notulen van denzelfden dag als deze brief blijkt, dat er toen kerkeraadsvergadering gehouden is op Dageraad, de gouvernementsplantage, en daarin is vastgesteld, dat ds. Muller met de „Adriana Petronella", gevoerd door Christoffel Cock, naar het vaderland vertrokken is, zijn gemeente dus verlaten heeft en het predikambt derhalve is vacant geworden. De ouderlingen George, Sitte en Hendrik waren door de negers vermoord. Met den predikant hadden de ouderlingen Eckardt en Pieter Schweitzer hun ,gereede Effecten" geborgen; laatstgenoemden waren met het schip van kapitein Pijnappel vertrokken. Ouderling Beudiker was uitgeweken naar Demerary.

21 December 1763 werd een kleine $f$ 1100.- naar Amsterdam overgemaakt met verzoek dit geld te bewaren voor de gemeente, tot beter tijden voor de kolonie zouden zijn aangebroken. Intusschen was ds. Muller 17 Augustus 1763 in de vergadering van het Amsterdamsche consistorie gekomen en had hij om betaling van zijn traktement, zijn reiskosten en vergoeding van andere schaden gevraagd. Men had hem daar naar ds. Klepperbein en ouderling Bon en naar zijn eigen kerkeraad en gemeente in Berbice verwezen. Toen de genoemde gecommitteerden de zaak weer in de vergadering brachten, bleek, dat ds. Muller het consistorie als gemachtigde van den kerkeraad in Berbice had doen dagvaarden voor Commissarissen van de kleine zaken te Amsterdam om $f 600$.- als een half jaar traktement uitbetaald te krijgen. Het bleek nu, dat het maar goed was, dat men de band met de gemeente ginds formeel zoo slap gehouden had. 8. November 1763 werd aan ds. Muller zijn eisch ontzegd.

(wordt vervolgd). 